\title{
A Rapid- and Short-Acting Hypoglycemic Agent KAD-1229 Improves Post-Prandial Hyperglycemia and Diabetic Complications in Streptozotocin-Induced Non-Insulin-Dependent Diabetes Mellitus Rats
}

\author{
Hideki Ohnota', Tsuyoshi Kitamura ${ }^{2}$, Mayumi Kinukawa ${ }^{1}$, Shuichiro Hamano', Nobuo Shibata ${ }^{2}$, \\ Hiroshi Miyata ${ }^{1}$ and Arao Ujiie ${ }^{1}$ \\ ${ }^{1}$ Central Research Laboratories and ${ }^{2}$ Second Research Laboratories, Kissei Pharmaceutical Co., Ltd., \\ 4365-1, Kashiwabara, Hotaka, Minamiazumi-gun, Nagano 399-83, Japan \\ Received January 17, 1996 Accepted May 23, 1996
}

\begin{abstract}
We investigated therapeutic effects of a rapid- and short-acting non-sulfonylurea hypoglycemic agent, calcium (2S)-2-benzyl-3-(cis-hexahydro-2-isoindolinylcarbonyl)propionate dihydrate (KAD-1229), on streptozotocin (STZ)-induced non-insulin-dependent diabetes mellitus (NIDDM) rats. The effects exerted by KAD-1229 on the post-prandial plasma glucose rise in STZ-induced mild NIDDM (mNIDDM) rats were different from those of sulfonylureas. When KAD-1229 with liquid meal $(10 \mathrm{kcal} / \mathrm{kg})$ was given to the mNIDDM rats, the plasma glucose migration was similar to that of normal healthy rats. On the contrary, glibenclamide had little or no effect on the plasma glucose rise $0.5-1 \mathrm{hr}$ after oral administration, and its effect was only evident $2-5 \mathrm{hr}$ after dosing. Tolbutamide showed similar hypoglycemia to that induced by glibenclamide at $2-5 \mathrm{hr}$ with insufficient efficacy at $0.5 \mathrm{hr}$. Gliclazide sufficiently suppressed the level of post-prandial plasma glucose. However, its complete inhibition of post-prandial plasma glucose was associated with the extra-hypoglycemia $1-5 \mathrm{hr}$ after oral administration. We also tested the efficacy of KAD-1229 in more severe STZ-induced NIDDM (sNIDDM) rats to elucidate the effects of the drug on the long-term glycemic controls and diabetic complications. When the SNIDDM rats were treated with $10 \mathrm{mg} / \mathrm{kg} \mathrm{KAD}-1229$ twice a day for about 17 weeks, increases in fasting plasma glucose and hemoglobin $\mathbf{A}_{1 \mathrm{c}}$ were inhibited. Furthermore, treatment with KAD-1229 suppressed the development of microalbuminuria and cortical cataract. We conclude that the rapid- and short-acting insulinotropic agent KAD-1229 is able to improve the deterioration in the glycemic controls and inhibit the development of diabetic complications in STZ-induced NIDDM rats.
\end{abstract}

Keywords: KAD-1229, Streptozotocin-induced non-insulin-dependent diabetes mellitus (NIDDM) rat, Hypoglycemic agent, Diabetic complication

Sulfonylureas (SUs) have been used widely for the treatment of non-insulin-dependent diabetes mellitus (NIDDM) patients all over the world. Their efficacy in patients is now convincing and appreciated. However, their main drawback seems to be frequent manifestations of hypoglycemia, and some of them often cause severe, prolonged and even fatal hypoglycemic episodes (1-4). These SU-induced hypoglycemic adverse effects occur more often in elderly patients or in those with renal insufficiencies or other underlying illness where food intake is transiently reduced. It is generally accepted that a shorter-acting hypoglycemic agent should be prescribed to patients who have a risk of hypoglycemia (5). In addition to the short duration of action, rapid onset of efficacy is also important. It is known that in patients with mild NIDDM (mNIDDM), the basal insulin secretion is fairly normal, while the post-prandial insulin secretion is impaired (6). Retardation and insufficiency of post-prandial insulin secretion are characteristics of this disorder (6). Therefore, a rapid- and short-acting insulinotropic agent will be expected to improve both the retardation and the insufficiency of insulin secretion in NIDDM subjects with less anticipated hypoglycemia.

Recently, two rapid- and short-acting non-sulfonylurea 
insulinotropic hypoglycemic agents, A-4166 (7) and KAD-1229 (8), have been developed, and they are presently in clinical trials. Both agents are reported to act more rapidly with a shorter duration of effect than any other SUs in normal fasting or glucose loaded rats and fasting beagle dogs. They are also reported to inhibit the ATP-sensitive potassium channel in pancreatic $\beta$-cells as well as SUs $(9,10)$. In the present study, we examined the acute and chronic effects of KAD-1229 in streptozotocin (STZ)-induced NIDDM rats.

Estimation of the acute and chronic effects of the hypoglycemic agents in the NIDDM animal model is an important theme for the development of anti-diabetic drugs. Especially, the effect of insulinotropic hypoglycemic agent on diabetic complications in NIDDM animal models has not been established. Serradas and coworkers reported that the long-term treatment with gliclazide improved the pancreatic function in NIDDM rats produced by 5 -day-old neonatal injection of STZ ( 80 $\mathrm{mg} / \mathrm{kg}$, i.p.) (11). On the other hand, Kawai et al. reported the failure of long-term gliclazide treatment of STZinduced NIDDM rats (12). Both of them examined the effects of repeated administration of gliclazide on the pancreatic function and insulin content in NIDDM rats. In addition to the contradiction, it was still unknown if there are any changes in the glycemic control and whether STZ-induced NIDDM rats develop diabetic complications. In the present study, we tested the efficacy of KAD-1229 in STZ-induced NIDDM rats. In the single oral administration experiment, we demonstrated that the hypoglycemic effects of KAD-1229 are different from those of SUs in STZ-induced mNIDDM rats. Furthermore, in the repeated oral administration test using STZinduced severe NIDDM rats, we estimated the long-term effect of KAD-1229 on hemoglobin $\mathrm{A}_{1 \mathrm{c}}\left(\mathrm{HbA}_{1 \mathrm{c}}\right)$, diabetic complications and pancreatic insulin content.

\section{MATERIALS AND METHODS}

\section{The meal tolerance test in the MNIDDM rats}

For the single oral administration experiment, 3-dayold neonates of Sprague Dawley (SD) rats (SLC, Shizuoka) were given $60 \mathrm{mg} / \mathrm{kg} \mathrm{STZ}$ intraperitoneally to produce comparatively mNIDDM rats. They were divided into groups by an oral glucose tolerance test (OGTT, 2 $\mathrm{g} / \mathrm{kg}$ ) at 5 weeks of age. The MNIDDM rats were housed in a condition-controlled room, and the liquid meal tolerance test was conducted at $11-13$ weeks of age. The liquid meal ( $\%$ in $w / v$ : 11.6 sucrose, 4.1 casein, 2.85 olive oil, 0.85 corn oil, 1.0 salt mixture, 0.5 vitamin mixture, 0.27 ethyl linoleate, 0.25 sodium carragheenate, 0.003 DL- $\alpha$-tocopherol acetate, 0.05 L-cystine and 0.03 DLmethionine; $10 \mathrm{kcal} / \mathrm{kg}$; Oriental Yeast, Tokyo) with hypoglycemic drugs or vehicle $(0.5 \%$ carboxymethyl cellulose) was administered to the mNIDDM rats at time zero. Blood was collected into ice-cold heparinized microtubes by the tail artery snipping following the time course. In this meal tolerance test, when a drug treatment induced lower plasma glucose than that of normal rats, we regarded this as unwanted hypoglycemia. Plasma glucose was determined by the glucose oxidase method using a commercial kit (Wako, Osaka). For the plasma insulin and glucagon determinations, blood was collected into an ice-cold tube containing heparin $(30 \mathrm{U} /$ tube; Kodama, Tokyo) and aprotinine ( $500 \mathrm{KIU} / \mathrm{ml}$ blood, bovine lung; Cosmo Bio, Tokyo) by decapitation. Plasma immunoreactive insulin (IRI) was determined by a commercial radioimmunoassay (RIA) kit (Eiken, Tokyo) using rat insulin (Novo, Denmark) as a standard. Plasma immunoreactive glucagon (IRG) was also determined by a commercial kit (Daiichi Radioisotope, Tokyo) using pork glucagon as a standard (13).

\section{The chronic administration test in the SNIDDM rats}

STZ $(60 \mathrm{mg} / \mathrm{kg})$ was injected into 6-day-old male SD rats to produce severe NIDDM (sNIDDM) animal models that develop diabetic complications within a short term. At 5 weeks of age, they were divided into groups by the OGTT $(2 \mathrm{~g} / \mathrm{kg})$. After checking pre-treatment $\mathrm{HbA}_{\mathrm{lc}}$ levels of the sNIDDM rats by an affinity column method (Glyc-Affin-GHb ${ }^{\mathrm{TM}}$; Seikagaku Corp., Tokyo) (14), repeated drug administration was initiated. KAD-1229 $(10 \mathrm{mg} / \mathrm{kg})$ was administered to the SNIDDM rats twice a day at 8-10 a.m. and 5-7 p.m. Pelleted rat chow (11 $\mathrm{g} /$ body/once, SLC) was given to the rats immediately after drug administration. The SNIDDM rats finished the chow within $2-3 \mathrm{hr}$. Changes in $\mathrm{HbA}_{1 \mathrm{c}}$ and fasting plasma glucose were checked periodically.

\section{Microalbuminuria determination}

The urine from the sNIDDM rats was collected at 21 weeks of age, and an enzyme-linked immunosorbent assay (ELISA) was done as follows: A 96-well, multi-well plate was coated with goat anti-rat albumin antibody (Organon, Durham, NC, USA) by overnight incubation at $4^{\circ} \mathrm{C}$. The plate was washed with phosphate-buffered saline (PBS) containing $0.05 \%$ Tween 20 and then blocked with PBS containing 10\% goat serum for $1 \mathrm{hr}$. Standard (rat albumin, Organon) and test samples were applied to the well and incubated for $1 \mathrm{hr}$ at room temperature. After washing three times with PBS containing Tween 20, peroxidase labeled goat anti-rat albumin IgG (Organon) was added to each well and incubated for $1 \mathrm{hr}$ at room temperature. Color development was conducted by a peroxidase color former kit (Sumiron ${ }^{\mathrm{TM}}$; Sumitomo, Tokyo), and the absorbance at $450 \mathrm{~nm}$ was measured. 
Creatinine concentrations in the urine were determined by an automatic analyzer (RA-1000; Technicon, Tokyo) (15).

\section{Histopathological analyses}

At 24 weeks of age, the rats were sacrificed. After whole blood collection from the abdominal aorta under ether anesthesia, an eyeball, the kidney and the pancreas were removed from each rat. Eyes were preserved in Davidson's fixative, and the kidneys and halves of the pancreas were preserved in buffered $10 \%$ formalin. These tissues were embedded in paraffin wax, and sections cut at 3-4 $\mu \mathrm{m}$ were stained with hematoxylin and eosin for histopathological examination. The sections of kidneys were stained with Masson trichrome stain. Histopathological findings were classified into four grades: no remarkable change (0), slight change (1), moderate change (2) and severe change (3).

\section{Determination of pancreatic insulin and glucagon content}

A half of each pancreas was dipped in the ice-cold acid ethanol extraction buffer $(0.15 \mathrm{M} \mathrm{HCl}, 75 \%$ (v/v) EtOH) for the determination of insulin and glucagon content. The half of the pancreas was minced by a disperser (Ultra Disperser $^{\mathrm{TM}}$; Yamato, Tokyo), and homogenized by a teflon homogenizer with 5 strokes. The homogenized tissue was extracted overnight at $4^{\circ} \mathrm{C}$, centrifuged at 3000 rpm for $30 \mathrm{~min}$, and the supernatant was collected. The pellet was homogenized and extracted overnight another 2 times. The combined supernatants was diluted 200 -fold and then subjected to RIA for insulin and glucagon determination.

\section{Chemicals}

KAD-1229 calcium (2S)-2-benzyl-3-(cis-hexahydro-2isoindolinylcarbonyl)propionate dihydrate was synthesized in our laboratory. Gliclazide was purchased from Dainihonseiyaku (Osaka). Glibenclamide and tolbutamide were from Sigma (St. Louis, MO, USA).

\section{Statistics}

Statistical analyses for the effect of several drugs in the single administration test were performed with ANOVA followed by Duncan's multiple comparison test. In the repeated administration test, data were analyzed by Student's $t$-test for the comparison with the control group. The incidence of cataract in SNIDDM rats was analyzed by the Williams Wilcoxon rank sum test. Data are expressed as means \pm S.E. unless stated otherwise.

\section{RESULTS}

Effect of KAD-1229 and SUS on post-prandial plasma glucose in $M N I D D M$ rats

When 1,3 or $10 \mathrm{mg} / \mathrm{kg} \mathrm{KAD}-1229$ with the liquid meal $(10 \mathrm{kcal} / \mathrm{kg})$ were administered to the mNIDDM rats, dose-dependent hypoglycemic effects were observed (Fig. 1a). KAD-1229, 1 and $3 \mathrm{mg} / \mathrm{kg}$, exerted its effects $0.5-2$ hr after oral administration, and there were no effects $3-5 \mathrm{hr}$ after dosing. It is noteworthy that these doses exerted sufficient suppression of post-prandial plasma glucose rise, and never lowered plasma glucose below the levels in normal rats (Fig. 1e). KAD-1229 at $10 \mathrm{mg} / \mathrm{kg}$ showed more prolonged reduction of plasma glucose, lasting up to $5 \mathrm{hr}$ after oral administration. However, its effect was not significant $5 \mathrm{hr}$ after dosing when compared with the normal rats. In the case of gliclazide, the dose of $1 \mathrm{mg} / \mathrm{kg}$ could not inhibit the enhancement of plasma glucose $0.5 \mathrm{hr}$ after administration, and a significant hypoglycemia was observed at $2 \mathrm{hr}$ after dosing (Fig. 1b). Although 3 or $10 \mathrm{mg} / \mathrm{kg}$ gliclazide showed sufficient reduction of post-prandial plasma glucose, adverse hypoglycemic effects were also observed at several time points during $5 \mathrm{hr}$ after oral administration. On the other hand, glibenclamide $(1,3$ and $10 \mathrm{mg} / \mathrm{kg}$ ) and tolbutamide $(3,10$ and $100 \mathrm{mg} / \mathrm{kg}$ ) showed marginal effects on the immediate increase in plasma glucose after dosing (Fig. 1: c and d). Instead, $2-5 \mathrm{hr}$ after oral administration of these drugs, the plasma glucose in the mNIDDM rats was significantly lower than that of the normal rats. In this experiment, differential effects of insulinotropic hypoglycemic agents in the mNIDDM rats were revealed (Fig. 1e).

Effect of KAD-1229 on plasma insulin and glucagon in the $m N I D D M$ rats

Next we investigated the effects of KAD-1229 on plasma insulin and glucagon levels in the MNIDDM rats (Fig. 2). When the liquid meal $(10 \mathrm{kcal} / \mathrm{kg})$ was administered to the mNIDDM rats, a significant enhancement of plasma insulin levels was observed at $0.5 \mathrm{hr}$ after dosing, and no change in plasma glucagon level was observed. When 3 $\mathrm{mg} / \mathrm{kg}$ KAD-1229 with the liquid meal was administered, super-impositions of plasma insulin were observed in the mNIDDM rats at 0.5 and $1 \mathrm{hr}$ after oral administration. This insulinotropic effect of KAD-1229 was most evident at $0.5 \mathrm{hr}$ after dosing. Plasma glucagon levels were unchanged.

Therapeutic effect of KAD-1229 on the glycemic control and diabetic complications in the SNIDDM rats

The mNIDDM rats described above showed neither an increase in $\mathrm{HbA}_{\mathrm{Ic}}$ nor development of diabetic complica- 
a) KAD-1229

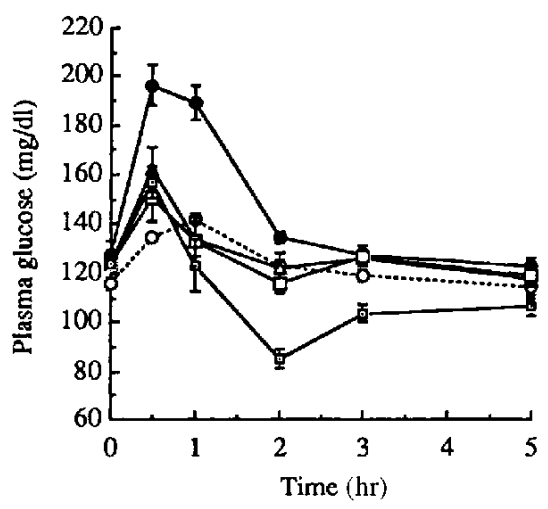

c) Glibenclamide

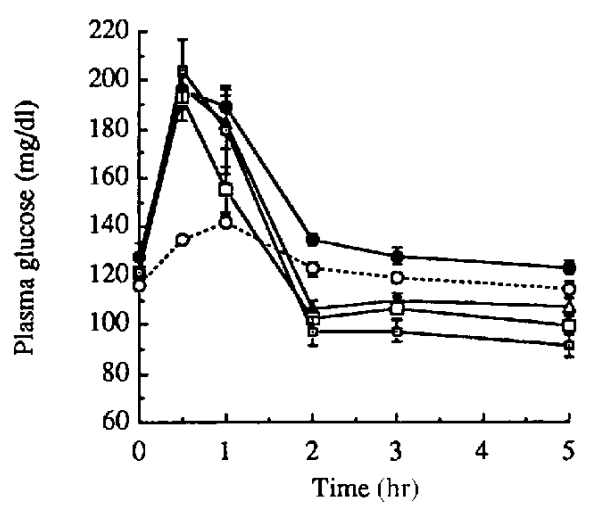

b) Gliclazide

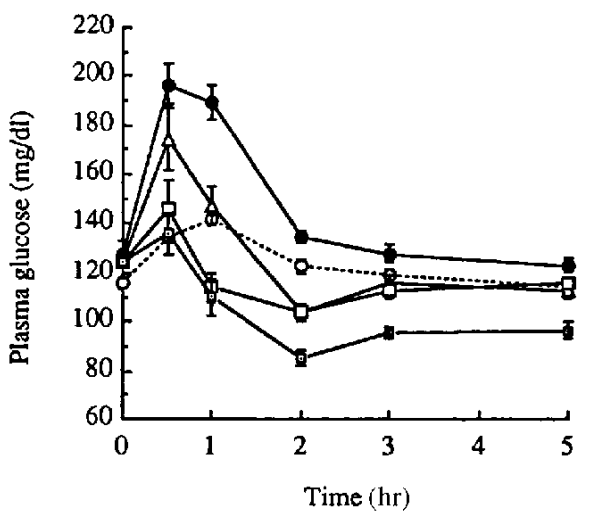

d) Tolbutamide

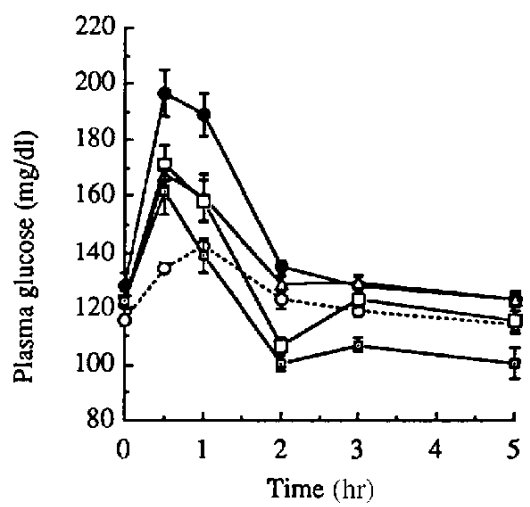

e)

\begin{tabular}{|cc:cccc|}
\hline & $\begin{array}{c}\text { Dose } \\
\text { (mg/kg) }\end{array}$ & \multicolumn{5}{c|}{ Time after oral administration } \\
(hr)
\end{tabular}

Fig. 1. The hypoglycemic effects of KAD-1229 and sulfonylureas in the meal tolerance test using the mNIDDM rats. KAD1229 (a), gliclazide (b), glibenclamide (c) or tolbutamide (d) were given to the fasting mNIDDM rats with the liquid meal (10 $\mathrm{kcal} / \mathrm{kg}$ ). Blood was collected by tail snipping according to the time course, and change in plasma glucose was monitored $(\mathrm{n}=9-10)$. Data are expressed as means \pm S.E. Control: $(\bigcirc)$; Normal: $(\bigcirc)$ KAD-1229: $1(\triangle), 3(\square), 10(\bullet) \mathrm{mg} / \mathrm{kg}$;

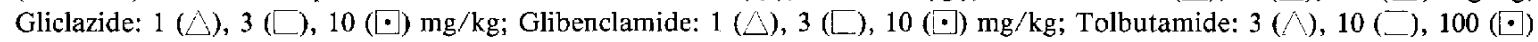
$\mathrm{mg} / \mathrm{kg}$. Statistical analyses of the meal tolerance test (e) are shown. The difference from the control mNIDDM rats is shown on the left of the oblique line, and that from the normal rats is shown on the right. + and ++ indicate a significantly higher value than the control with $P<0.05$ and $P<0.01$, respectively. - and -- indicate a significantly lower value with $P<0.05$ and $P<0.01$, respectively. The square indicates the ideal plasma glucose level, and the shaded square shows a lower value than that of the normal rats (hypoglycemia). ns: not significant. Data were analyzed by ANOVA followed by Duncan's multiple comparison test. 


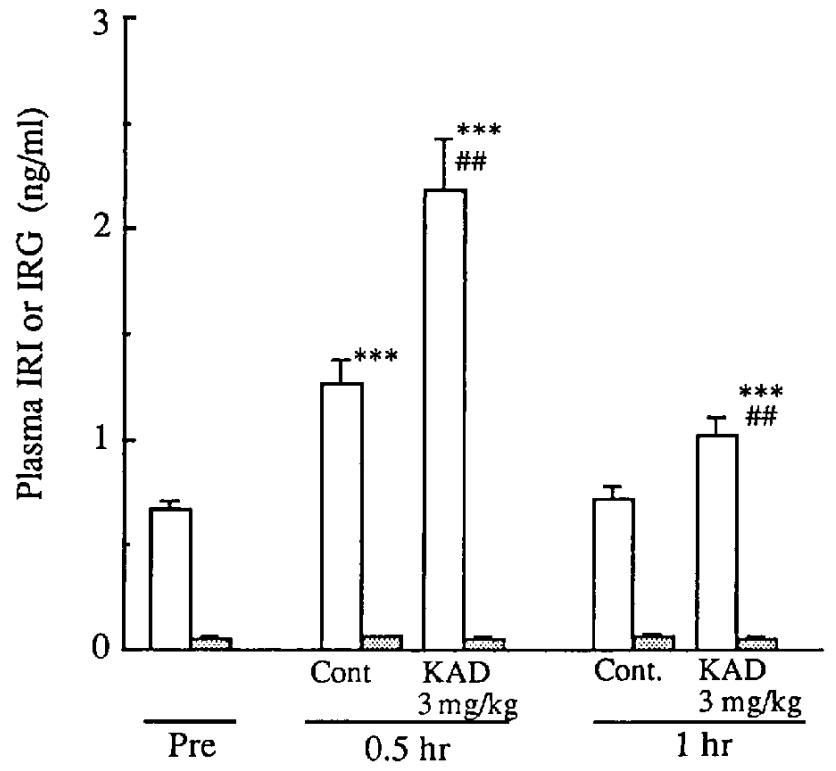

Fig. 2. Changes in plasma insulin and glucagon levels in the mNIDDM rats. Ten $\mathrm{kcal} / \mathrm{kg}$ liquid meal with or without $3 \mathrm{mg} / \mathrm{kg}$ KAD-1229 was administered to the MNIDDM rats, and blood was collected by decapitation at pre-administration, 0.5 and $1 \mathrm{hr}$ after dosing. Plasma immunoreactive insulin (IRI, ${ }_{-}^{-}$) and glucagon (IRG, $\mathrm{B}$ ) were determined by commercial RIA kits. Data are expressed as means \pm S.E. $(\mathbf{n}=10)$. ${ }^{* *}$ : significant difference from the pre-administration with $\mathrm{P}<0.001$ and ${ }^{\#}$ : significant difference from the control with $\mathrm{P}<0.01$ by Student's $t$-test.

tions during 6 months after birth (data not shown). Therefore, we produced the more severe NIDDM (sNIDDM) rat model to evaluate the long-term efficacy of KAD-1229. Intraperitoneal injection of $60 \mathrm{mg} / \mathrm{kg} \mathrm{STZ}$ to 6-day-old SD rat neonates induced more severely impaired glucose tolerance in the SD rats at 5 weeks of age (data not shown). In the preliminary experiment using the sNIDDM rats at $16-18$ weeks of age, $10 \mathrm{mg} / \mathrm{kg} \mathrm{KAD-}$ 1229 exerted a significant hypoglycemic effect on the fasting plasma glucose, while $3 \mathrm{mg} / \mathrm{kg} \mathrm{KAD}-1229$ failed to lower the plasma glucose (data not shown). Severe NIDDM rats were less sensitive to the agent than mNIDDM rats were. Therefore, we used the dose of 10 $\mathrm{mg} / \mathrm{kg} \mathrm{KAD}-1229$ for the chronic administration test.

At the time of grouping (at 5 weeks of age), the sNIDDM rats showed normal fasting plasma glucose, like the mNIDDM rats (Fig. 3a). Fasting plasma glucose in the sNIDDM rats became dramatically elevated by 9 weeks age. $\mathrm{HbA}_{1 \mathrm{c}}$ in the 5-week-old SNIDDM rats was significantly higher than that in the normal rats, but was still at a very low level (Fig. $3 \mathrm{~b}$ ). $\mathrm{HbA}_{1 \mathrm{c}}$ in the control sNIDDM rats increased and reached a plateau of around $12 \%$ at 13 weeks of age, while that in the normal rats also increased but was below $5 \%$. Chronic treatment by 10 $\mathrm{mg} / \mathrm{kg} \mathrm{KAD}-1229$ suppressed the increase in $\mathrm{HbA}_{\mathrm{lc}}$ in the
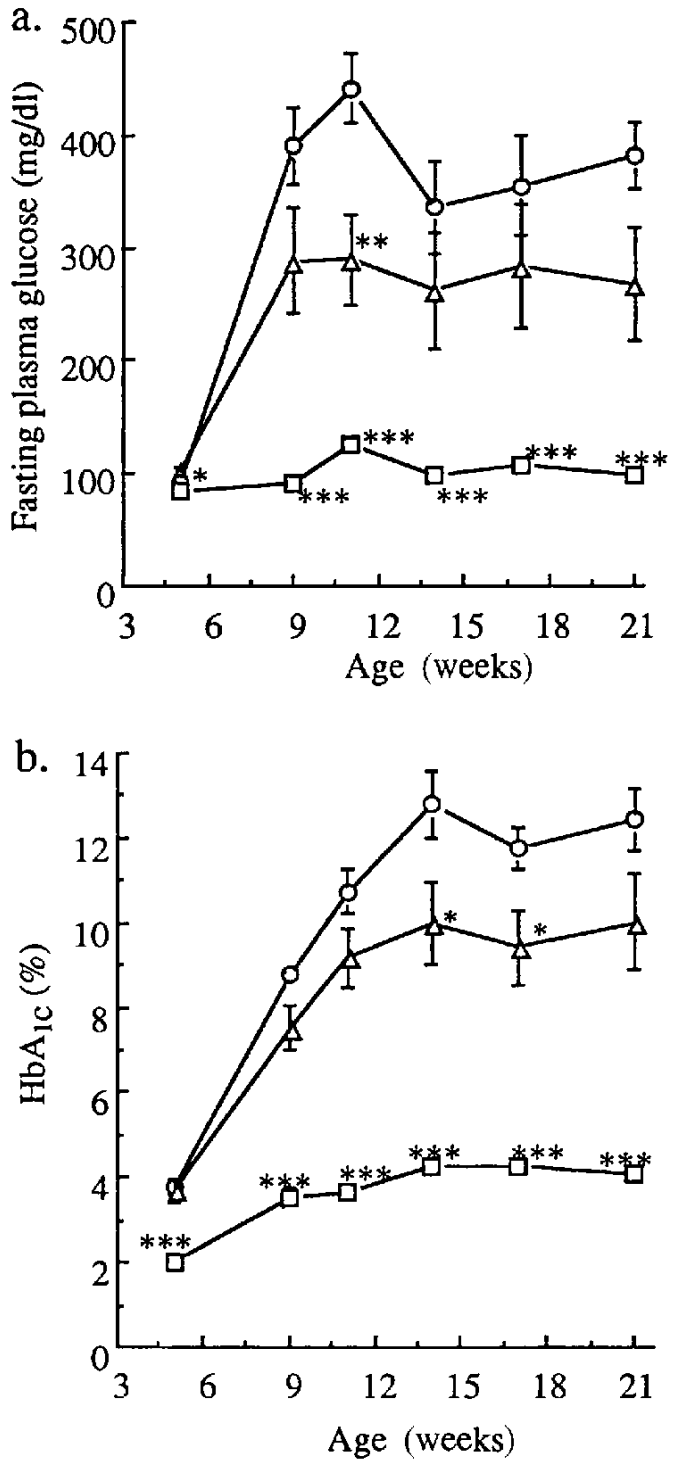

Fig. 3. Changes in fasting plasma glucose (a) and $\mathrm{HbA}_{\mathrm{lc}}$ (b) in sNIDDM rats that were treated with vehicle $(C)$ or $10 \mathrm{mg} / \mathrm{kg} \mathrm{KAD-}$ 1229 ( $\triangle$ ) from 7 through 23 weeks of age. The change in normal rats (!) was also shown. KAD-1229 $(10 \mathrm{mg} / \mathrm{kg})$ was administered to sNIDDM rats twice a day just before feeding. Blood samples for the fasting plasma glucose and $\mathrm{HbA}_{\mathrm{ic}}$ were collected from the tail vein using a 26-gauge needle. The fasting plasma glucose in the drugtreated group at 5 weeks of age was significantly higher than that in the control sNIDDM rats. Data are expressed as means \pm S.E. * and ****: significant difference from the control with $\mathrm{P}<0.05$ and $\mathrm{P}<0.001$, respectively, by Student's $t$-test. (sNIDDM rats: $n=8$, normal rats: $\mathrm{n}=9-10$ ).

SNIDDM rats, and its effect was significant at 13 and 16 weeks of age (Fig. 3b).

At 21 weeks of age, albumin concentrations in the urine collected from the SNIDDM rats were determined by ELISA (Fig. 4). The SNIDDM rats treated with the vehicle showed significantly larger albumin leakage compared with the normal rats. This pre-nephropathy symp- 


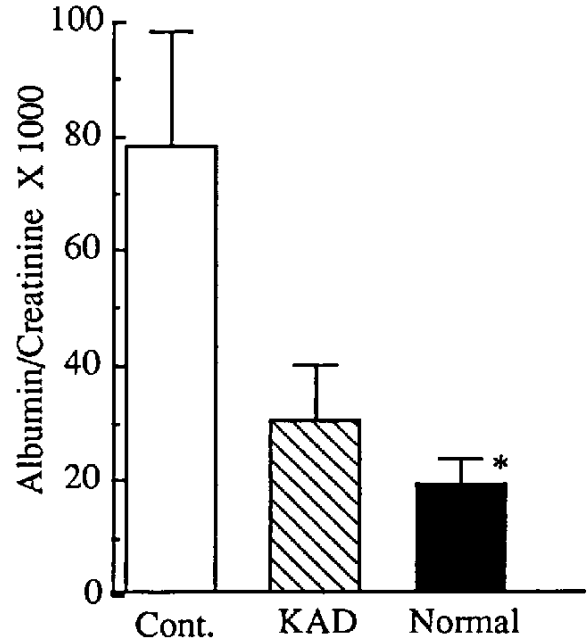

Fig. 4. Effects of chronic treatment with KAD-1229 on the albuminuria in SNIDDM rats. At 21 weeks of age, sNIDDM rats were fasted for about $13 \mathrm{hr}$, and the urine was collected from 13:00 through 17:00. Creatinine concentration in the urine was determined by the autoanalyzer, and albumin concentration was determined by ELISA as described in Materials and Methods. Data are expressed as means \pm S.E. $(n=8-9){ }^{*}$ : significant difference from the control with $\mathrm{P}<0.05$.

tom in SNIDDM rats was confirmed by the histopathological analyses. All sNIDDM rats used in this study showed mild thickening of the mesangial basement membrane (Table 1). The SNIDDM rats treated with KAD1229 showed reduction of microalbuminuria, although its effect was not significant (Fig. 4).

Table 1. Histopathological findings in SNIDDM rats that received chronic treatment with KAD-1229

\begin{tabular}{|c|c|c|c|c|}
\hline Organ & $\begin{array}{c}\text { Treatment } \\
\text { (n) }\end{array}$ & $\begin{array}{c}\text { Control } \\
\text { (8) }\end{array}$ & $\begin{array}{c}\mathrm{KAD}-1229 \\
10 \mathrm{mg} / \mathrm{kg} \\
(8)\end{array}$ & $\begin{array}{c}\text { Normal } \\
\text { (9) }\end{array}$ \\
\hline Findings & Grade & 0123 & 0123 & 0123 \\
\hline \multicolumn{5}{|l|}{ Eye } \\
\hline Cortical cataract & & $\begin{array}{llll}0 & 0 & 1 & 7\end{array}$ & ${ }^{\mathrm{a}} 311113$ & $\begin{array}{llll}b_{9} & 0 & 0 & 0\end{array}$ \\
\hline Retinal vacuolatio & ion & 5300 & 6200 & 7200 \\
\hline \multicolumn{5}{|l|}{ Pancreas } \\
\hline Atrophy of islet & & 0044 & 0062 & 90000 \\
\hline Hyaline degenerat & ation of islet & 07110 & 08000 & 9000 \\
\hline \multicolumn{5}{|l|}{ Kidney } \\
\hline Nephroblastoma & & $\begin{array}{llll}5 & 0 & 2 & 1\end{array}$ & 80000 & 9000 \\
\hline Focal hyperplasia & a of tubules & 8000 & 7100 & 9000 \\
\hline $\begin{array}{l}\text { Thickening of glo } \\
\text { basement memb }\end{array}$ & $\begin{array}{l}\text { omerular } \\
\text { brane }\end{array}$ & $\begin{array}{llll}0 & 8 & 0 & 0\end{array}$ & 0800 & 9000 \\
\hline
\end{tabular}

0: No remarkable change, 1: Slight change, 2: Moderate change, 3: Severe change. Incidence of cortical cataract was analyzed by the Williams Wilcoxon rank sum test. ${ }^{a}$ and ${ }^{b}$ : significant difference from the control with $\mathbf{P}<0.05$ and 0.01 , respectively.
The histopathological findings in each group are summarized in Table 1. Almost all animals in the control sNIDDM rats developed severe cataract, whereas the drug treated sNIDDM rats showed significant improvement (Table 1, Fig. 5). As anticipated, atrophy of pancreatic islets was observed in the SNIDDM rats, and these islets showed hyaline degeneration. In kidneys, a nephroblastoma was observed in a few animals in addition to thickening of the glomerular basement membrane (Table 1).

The pancreatic insulin content in SNIDDM rats was about one-twentieth that of normal rats (Fig. 6a). The insulin content was not affected by the treatment with KAD-1229. The glucagon content of the pancreas was not changed between the control SNIDDM rats and the normal rats, and no effect of the drug on pancreatic glucagon content was observed (Fig. 6b).

\section{DISCUSSION}

We have previously reported that KAD-1229 normalized the impaired glucose tolerance in the oral glucose tolerance test $(2 \mathrm{~g} / \mathrm{kg})$ using the mildest STZ-induced NIDDM rats which received $30 \mathrm{mg} / \mathrm{kg} \mathrm{STZ}$ at 1.5 days of age (16). In the report, we showed that KAD-1229 normalized the impaired glucose tolerance in rats injected with $30 \mathrm{mg} / \mathrm{kg} \mathrm{STZ}$, but not in rats injected with 60 $\mathrm{mg} / \mathrm{kg} \mathrm{STZ}$ at 1.5 days after birth (16). However, we noticed that the oral glucose route provokes a more rapid and higher plasma glucose rise than food intake does. Thus, using the liquid meal, we clarified the differential effect of oral hypoglycemic agents in MNIDDM rats that received $60 \mathrm{mg} / \mathrm{kg}$ STZ at 3 days of age. KAD-1229 acted more rapidly and had a shorter duration than SUs did in the mNIDDM rats. While glibenclamide and tolbutamide failed to inhibit the post-prandial plasma glucose rise, KAD-1229 suppressed the post-prandial plasma glucose rise efficiently without extra hypoglycemia owing to its rapid onset and short duration of efficacy. In these experiments, we regarded the lower plasma glucose of mNIDDM rats, relative to that of normal rats, as unnecessary hypoglycemia. When a drug induced a small amount of hypoglycemia, it will increase the risk of severe hypoglycemia which can be induced by some additional factors (i.e., exercise, alcohol intake and so forth). Therefore, the most rapid and shortest-acting KAD-1229 among the reported hypoglycemic agents (8) is considered to be useful, especially for inhibiting post-prandial plasma glucose rise without extra hypoglycemia. This rapid and short action of KAD-1229 is due to its rapid adsorption and excretion (17), and it will provide an alternative choice for the optimal glycemic control in the treatment of NIDDM subjects.

We also demonstrated the insulinotropic effect of 
A

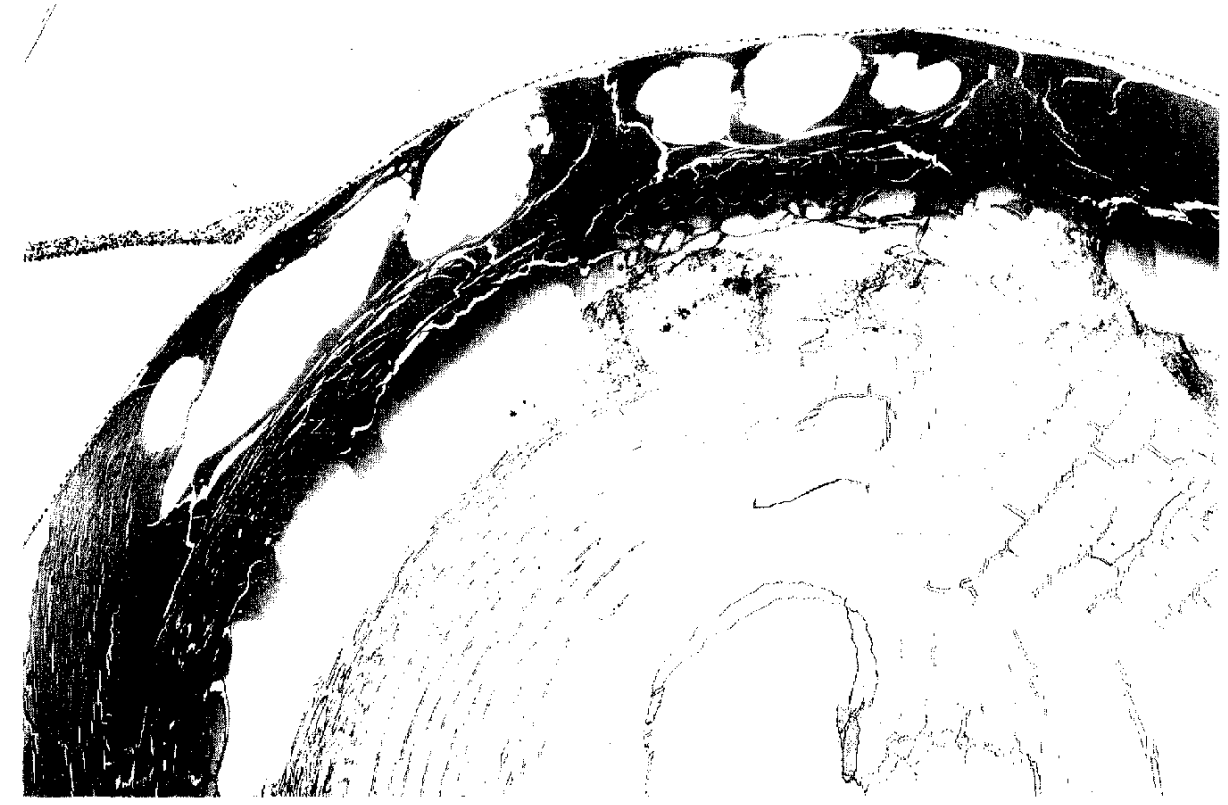

B

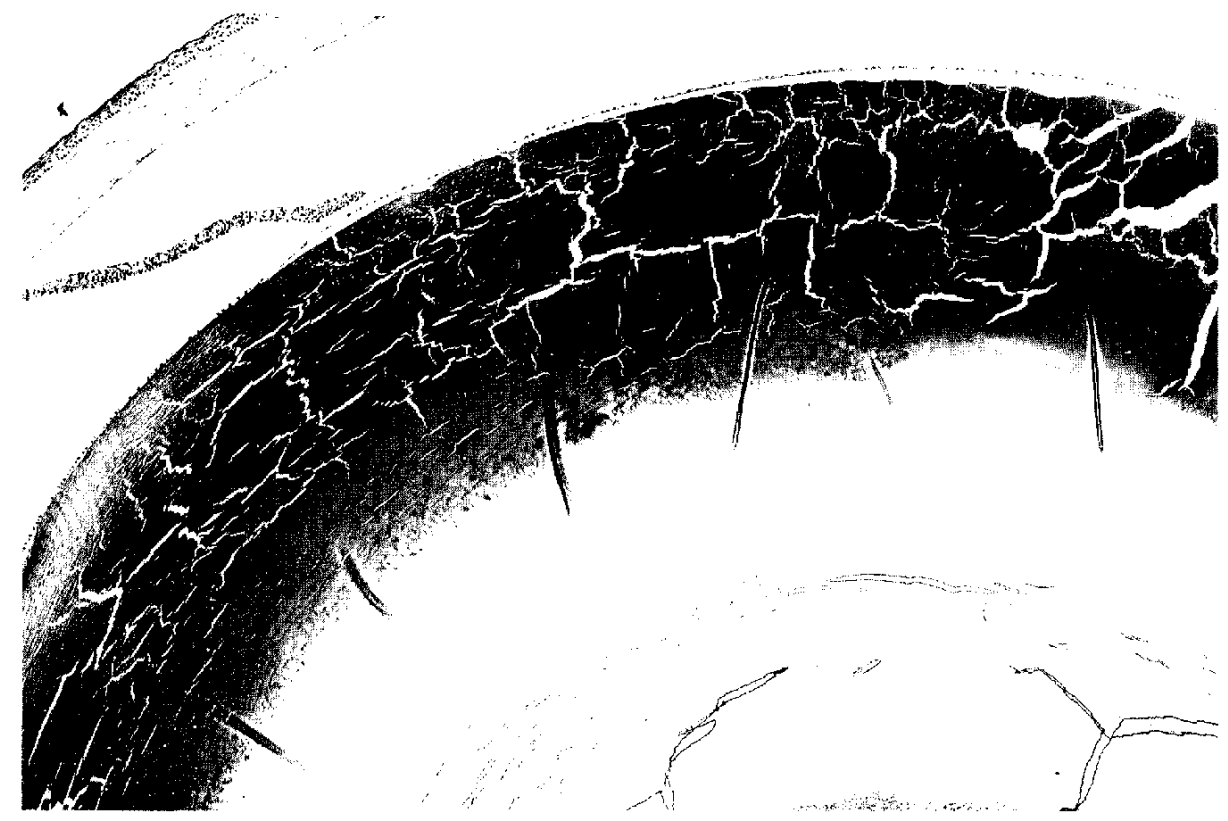

Fig. 5. Representative microphotographs of leticular sections stained with hematoxylin and eosin. $\times 13$. A: Control, histopathological grade 3. Degeneration in the lens cortex in a rat of the control group that was grossly observed to have complete opacity of the lens. Lenticular fibrous tissues show severe ballooning and widespread destruction. B: KAD-1229, $10 \mathrm{mg} / \mathrm{kg}$ group, histopathological grade 1 . The lens cortex in a rat treated with KAD-1229 was composed of slightly irregularly arranged fibrous tissue, while it shows minimum vacuolated degeneration.

KAD-1229 in the mNIDDM rat model. KAD-1229 showed no effect on the plasma glucagon content, although we observed its inhibitory effect on glucagon release induced by the hypoglycemia in the perfused pancreas of the rat (18). It is probable that KAD-1229 inhibits glucagon release only when it was stimulated. Thus, the inhibitory effect of KAD-1229 on post-prandial plasma glucose rise in MNIDDM rats was thought to be ascribed to the additional insulin release by the drug.

We produced SNIDDM rats associated with severely degenerated $\beta$-cells, to elucidate the long-term efficacy of KAD-1229. At 5 weeks of age when OGTT for grouping was done, the SNIDDM rats showed normal fasting plasma glucose values. This might reflect some recovery of $\beta$ cell mass as described previously (19) and indicate that the pancreatic function in the SNIDDM rats was sub-normal 

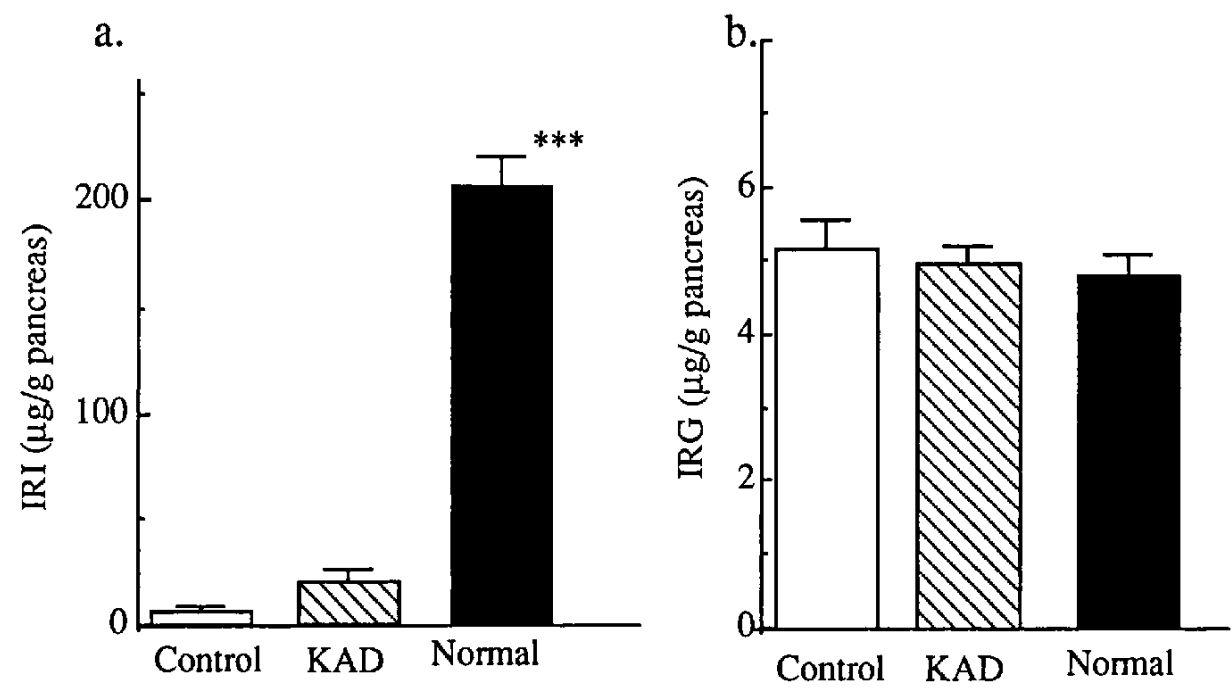

Fig. 6. Effect of the chronic treatment with KAD-1229 on pancreatic insulin (a) and glucagon (b) contents in sNIDDM rats. The rats were sacrificed at 24 weeks of age, and the pancreatic insulin and glucagon was extracted by the acid-ethanol method as described in Materials and Methods. Immunoreactive insulin (IRI) and glucagon (IRG) were determined by commercial kits. Data are expressed as means \pm S.E. $(n=8-9)$. ${ }^{* *}$ : significant difference from the control with $\mathrm{P}<0.001$.

at that age. However, the glycemic control in the sNIDDM rats was abruptly deteriorated within an additional four weeks. In the repeated administration test of KAD-1229, it exerted suppressive effects on $\mathrm{HbA}_{1 \mathrm{c}}$ and the fasting plasma glucose in the SNIDDM rats. Furthermore, the chronic treatment by KAD-1229 improved the cortical cataract and microalbuminuria. These efficacies were all thought to be ascribed to the insulinotropic hypoglycemic effect of KAD-1229 as no extrapancreatic effect for this drug was reported so far. Serradas et al. reported that rats that received $80 \mathrm{mg} / \mathrm{kg} \mathrm{STZ}$ at 5 days of age could be both responsive and non-responsive to the gliclazide (11). They demonstrated the long-term efficacy of gliclazide in the responsive rats. We did not distinguish the responsive SNIDDM rats from the non-responsive ones. However, the effect of KAD-1229 on the glycemic control animals and diabetic complications showed large deviations (Figs. 3 and 4, Table 1), and this may be explained by the presence of non-responsive SNIDDM rats as previously reported (11).

In conclusion, we demonstrated the short- and longterm efficacy of KAD-1229 in STZ-induced NIDDM rats. In the single administration experiment, we showed the differential effect of oral hypoglycemic agents. In the repeated administration experiment, we demonstrated the suppressive effect of KAD-1229 on the development of diabetic complications. In addition, the severe NIDDM rats induced by the neonatal injection of STZ was shown to be a useful animal model to estimate drug efficacies and also to be valid for studying the etiology of diabetic complications.

\section{Acknowledgments}

We thank Mr. Koizumi for technical asistance.

\section{REFERENCES}

1 Jackson JE and Bressler R: Clinical pharmacology of sulfonylurea hypoglyceamic agents (Part 1). Drugs 22, 211-245 (1981)

2 Jackson JE and Bressler R: Clinical pharmacology of sulfonylurea hypoglyceamic agents (Part 2). Drugs 22, 295-320 (1981)

3 Berger W: Incidence of severe side effects during therapy with sulfonylureas and biguanides. Horm Metab Res 17, Supp 15, $111-115$ (1985)

4 Jennings AM, Wilson RM and Ward JD: Symptomatic hypoglycemia in NIDDM patients treated with oral hypoglycemic agents. Diabetes Care 12, 203-208 (1989)

5 Alberti KGMM and Gries FA: Management of non-insulindependent diabetes mellitus in Europe: A consensus view. Diabetic Med 5, 275-281 (1988)

6 Polonsky KS, Given BD, Hirsch LJ, Tillil H, Shapiro ET, Beebe C, Frank BH, Galloway JA and Cauter EV: Abnormal patterns of insulin secretion in non-insulin-dependent diabetes mellitus. N Engl J Med 318, 1231 - 1239 (1988)

7 Sato $\mathrm{Y}$, Nishikawa $\mathrm{M}$, Shinkai $\mathbf{H}$ and Sukegawa E: Possibility of ideal blood glucose control by a new oral hypoglycemic agent, $\quad N$-[(trans-4-isopropylcyclohexyl)-carbonyl]-D-phenylalanine (A-4166), and its stimulatory effect on insulin secretion in animals. Diabetes Res Clin Prac 12, 53-60 (1991)

8 Ohnota H, Koizumi T, Tsutsumi N, Kobayashi M, Inoue S and Sato F: Novel rapid- and short-acting hypoglycemic agent, a calcium (2S)-2-benzyl-3-(cis-hexahydro-2-isoindolinylcarbonyl) propionate (KAD-1229) that acts on the sulfonylurea receptor: comparison of effects between KAD-1229 and gliclazide. J Pharmacol Exp Ther 269, 489-495 (1994)

9 Akiyoshi $M$, Kakei $M$, Nakazaki $M$ and Tanaka $H$ : A new hypoglycemic agent, A-4166, inhibits ATP-sensitive potassium 
channels in rat pancreatic $\beta$-cells. Am J Physiol 268, E185-E193 (1995)

10 Mogami H, Shibata H, Nobusawa R, Ohnota H, Satou F, Miyazaki $\mathbf{J}$ and Kojima $\mathbf{I}$ : Inhibition of ATP-sensitive $\mathrm{K}^{+}$ channel by a non-sulfonylurea compound KAD-1229 in a pancreatic $\beta$-cell line, MIN 6 cell. Eur J Pharmacol 269, 293-298 (1994)

11 Serradas P, Bailbé D and Portha B: Long-term gliclazide treatment improves the in vitro glucose-induced insulin release in rats with type 2 (non-insulin-dependent) diabetes induced by neonatal streptozotocin. Diabetologia 32, 577-584 (1989)

12 Kawai K, Suzuki S, Murayama Y, Watanabe Y and Yamashita $K$ : Comparison of $\beta$-cell function after long-term treatment with either insulin, insulin plus gliclazide or gliclazide in neonatal streptozotocin-induced non-insulin-dependent diabetic rats. Diabetes Res Clin Pract 12, 163-172 (1991)

13 Nishino T, Kodaira T, Shin S, Imagawa K, Shima K, Kumahara $\mathrm{Y}$, Yanaihara $\mathrm{C}$ and Yanaihara $\mathrm{N}$ : Glucagon radioimmunoassay with use of antiserum to glucagon C-terminal fragment. Clin Chem 27, 1690-1697 (1981)

14 Yue DK, McLennan S, Church DB and Turtle JR: The measurement of glycosylated hemoglobin in man and animals by aminophenylboronic acid affinity chromatography. Diabetes 31, 701-705 (1982)

15 Chasson AL, Grady HJ and Stanley MA: Determination of creatinine by means of automatic chemical analysis. Am J Clin Pathol 35, 83-88 (1961)

16 Ohnota $H$, Koizumi $T$, Kobayashi M, Momose $Y$ and Sato F: Normalization of impaired glucose tolerannce by the short-acting hypoglycemic agent calcium $(2 S)$-2-benzyl-3-(cis-hexahydro2-isoindolinylcarbonyl) propionate dihydrate (KAD-1229) in non-insulin-dependent diabetes mellitus rats. Can J Physiol Pharmacol 73, 1-6 (1995)

17 Ohnota H, Miyagi M, Miyata H, Inoue S and Sato F: Characterization of a rapid- and short-acting non-sulfonylurea hypoglycemic agent, KAD-1229. Abstract of 15 th International Diabetes Federation Congress, Kobe, 10A5PP1074 (1994)

18 Kinukawa M, Ohnota $\mathrm{H}$ and Ajisawa $\mathrm{Y}$ : Effect of a non-sulfonylurea hypoglycemic agent, KAD-1229 on hormone secretion in the isolated perfused pancreas of the rat. $\mathrm{Br} \mathrm{J}$ Pharmacol 117, 1702-1706 (1996)

19 Bonner-Weir S, Trent DF, Honey RN and Weir GC: Responses of neonatal rat islets to streptozotocin. Limited B-cell regeneration and hyperglycemia. Diabetes 30, 64-69 (1981) 